\title{
Low-temperature positron-lifetime studies of proton-irradiated silicon
}

\author{
Mäkinen, S.; Rajainmäki, H.; Linderoth, Søren
}

Published in:

Physical Review B

Link to article, DOI:

10.1103/PhysRevB.42.11166

Publication date:

1990

Document Version

Publisher's PDF, also known as Version of record

Link back to DTU Orbit

Citation (APA):

Mäkinen, S., Rajainmäki, H., \& Linderoth, S. (1990). Low-temperature positron-lifetime studies of protonirradiated silicon. Physical Review B, 42(17), 11166-11173. https://doi.org/10.1103/PhysRevB.42.11166

\section{General rights}

Copyright and moral rights for the publications made accessible in the public portal are retained by the authors and/or other copyright owners and it is a condition of accessing publications that users recognise and abide by the legal requirements associated with these rights.

- Users may download and print one copy of any publication from the public portal for the purpose of private study or research.

- You may not further distribute the material or use it for any profit-making activity or commercial gain

- You may freely distribute the URL identifying the publication in the public portal

If you believe that this document breaches copyright please contact us providing details, and we will remove access to the work immediately and investigate your claim 


\title{
Low-temperature positron-lifetime studies of proton-irradiated silicon
}

\author{
S. Mäkinen and H. Rajainmäki* \\ Department of Physics, University of Jyväskylä, SF-40100 Jyväskylä, Finland \\ S. Linderoth \\ Laboratory of Applied Physics, Technical University of Denmark, DK-2800 Lyngby, Denmark
}

(Received 30 April 1990)

\begin{abstract}
The positron-lifetime technique has been used to identify defects created in high-purity singlecrystal silicon by irradiation with $12-\mathrm{MeV}$ protons at $15 \mathrm{~K}$, and the evolution of the defects has been studied by subsequent annealings between 20 and $650 \mathrm{~K}$. Two clear annealing steps were seen in the samples, the first starting at $100 \mathrm{~K}$ and the other at $400 \mathrm{~K}$. The first is suggested to be a result of the migration of free, negatively charged monovacancies, and the second is connected to the annealing of some vacancy-impurity complexes, probably negatively charged vacancy-oxygen pairs. The specific trapping rate of positrons to both of these negatively charged monovacancy-type defects has been found to have a clear $T^{-0.5}$ dependence. The positron lifetime in perfect $\mathrm{Si}$ is measured to be $217 \pm 1 \mathrm{ps}$, and the monovacancy lifetime is found to be $275 \pm 5 \mathrm{ps}$. Also the negatively charged vacancy-oxygen complexes were found, both experimentally and theoretically, to give rise to a positron lifetime of about 275 ps.
\end{abstract}

\section{INTRODUCTION}

Silicon is technologically the most important semiconductor so far. It is employed in almost all modern hightechnology products such as chips, solar cells, and transistors. At the moment the industry can produce quite high-quality $\mathrm{Si}$-based components thanks to the development of the crystal growth and thin-film techniques. However, present techniques cannot prevent the existence of different atomic-size defects ${ }^{1}$ in silicon. In many cases, such as the space technology, also particle radiation induces point defects in the Si-based components. These point defects can often have drastic effects on the electrical and optical properties of $\mathrm{Si}^{2,3}$ It is thus important to achieve knowledge about the properties of the defects, as well as the changes they cause to the electronic structure and the carrier densities in the host matrix. In addition to its technological importance, the study of point defects in $\mathrm{Si}$ also gives fundamental knowledge about the properties of atomic-size defects in semiconductors in general, and can aid the investigations of, e.g., the more complex GaAs.

Various experimental techniques have been developed for studies of point defects in solids since the early 1950's. For semiconductors the methods most often used are the electron paramagnetic resonance (EPR), ${ }^{4}$ infrared spectroscopy (IR), ${ }^{5}$ transient capacitance spectroscopy (TCS), ${ }^{6}$ deep-level transient spectroscopy (DLTS), ${ }^{7}$ highvoltage electron microscopy, ${ }^{8}$ and positron-annihilation spectroscopies (PAS). ${ }^{9-11}$ Due to the positive charge of positrons the positron-lifetime technique is selectively sensitive to negatively charged and neutral vacancy-type defects. The electron density in a vacancy is lower than that in the interstitial regions of the perfect lattice. Therefore, the lifetime of positrons trapped at a monova- cancy in $\mathrm{Si}$ is about $25 \%$ longer than the lifetime of those positrons that annihilate in the perfect crystal. ${ }^{12}$ The sensitivity of the positron-lifetime technique to open-volume defects is excellent: in semiconductors, defect concentrations of the order of $0.1 \mathrm{ppm}$ or less can be detected by this method. ${ }^{13}$

The density of states in semiconductors is characterized by the band gap, and in totally pure intrinsic conditions the Fermi level is (at zero temperature) in the middle of the gap. However, semiconductors always contain at least a small amount of point defects which can create electron energy levels in the gap. According to the occupation of these levels the Fermi level can vary from the top of the valence band to the bottom of the conduction band. The value of the Fermi energy determines the charge state of the vacancy, which in the case of $\mathrm{Si}$ is $-2 e,-e, 0$, or $2 e\left(V^{+}\right.$is found to be unstable $\left.{ }^{14-16}\right)$. The vacancy charge state makes the trapping of positrons very complex. In spite of intensive studies all the effects are not yet fully understood.

We have employed the positron-lifetime technique to study the annealing of vacancies in Si. High-purity single-crystal samples have been irradiated at $15 \mathrm{~K}$ with $12 \mathrm{MeV}$ protons and the samples have, thereafter, been isochronally annealed up to $650 \mathrm{~K}$. The positron-lifetime spectra were measured at $15 \mathrm{~K}$. Two annealing steps were clearly seen. The first started at about $100 \mathrm{~K}$ where free, negatively charged monovacancies are believed to become mobile. ${ }^{17}$ The other annealing step started at about $400 \mathrm{~K}$, and the samples were totally annealed at $600 \mathrm{~K}$. We have also studied the dependence of the relative vacancy concentration on the dose. With a dose of $2.3 \times 10^{14}$ protons $/ \mathrm{cm}^{2}$ the defect concentration, as observed by the positron-lifetime technique, was about eight times larger than the concentration produced by a 
$3.0 \times 10^{13} \mathrm{p} / \mathrm{cm}^{2}$ irradiation. We have studied the temperature dependence of the positron trapping rate in proton-irradiated $\mathrm{Si}$ and found good agreement with a theory recently proposed by Puska et al. ${ }^{18}$

\section{EXPERIMENT}

The Si samples were cut from a high-purity floatingzone (FZ)-grown single crystal rod made at Topsil Semiconductors a/s, Denmark. The resistivity of the material was $2200 \Omega \mathrm{cm}$ and the material was slightly $n$-type. The concentrations of phosphorus and boron were $5.8 \times 10^{-5}$ ppm $\mathbf{P}$ and $2.0 \times 10^{-5} \mathrm{ppm} \mathbf{B}$. The carbon and oxygen contents were $<0.3 \mathrm{ppm} \mathrm{C}$ and $<0.2 \mathrm{ppm} \mathrm{O}$. The samples were mechanically polished with $50 \mathrm{~mol} \% \mathrm{Al}_{2} \mathrm{O}_{3}, 30$ mol \% $\mathrm{SiO}_{2}$ powder to a thickness of $467 \mu \mathrm{m}$. After polishing, the $\mathrm{Si}$ samples were washed in deionized water and acetone before etching in 95 vol \% $\mathrm{HNO}_{3}$ and 5 vol \% HF for $1-1 \frac{1}{2}$ hours. Samples with thicknesses of $396 \pm 3 \mu \mathrm{m}$ and $387 \pm 1 \mu \mathrm{m}$ were prepared. Finally, the samples were rinsed in deionized water and acetone again.

The samples were packed in the standard sandwich geometry ${ }^{19}$ to let the positron source be covered by two identical pieces of $\mathrm{Si}$. The ${ }^{22} \mathrm{NaCl}$ positron source was deposited onto thin Havar foil $\left(1.7 \mathrm{mg} / \mathrm{cm}^{2}\right)$ and then developed. The proton irradiations were carried out by the JYFL low-temperature irradiation facility ${ }^{20}$ where the temperature of the specimens can be kept continuously at $15 \mathrm{~K}$ during and after irradiation, and annealings could thus be started from $15 \mathrm{~K}$. The lifetime spectrometer consists of a plastic scintillator for the start gamma $(1.275 \mathrm{MeV})$ and of a $\mathrm{BaF}_{2}$ scintillator for the stop gamma $(511 \mathrm{keV})$. Each positron-lifetime spectrum contained about 1.1 million events. The annealing rate was $25 \mathrm{~K} / \mathrm{h}$, and the isochronal annealings were carried out either in vacuum $\left(T_{\text {ann }} \leq 320 \mathrm{~K}\right)$ or in flowing argon $\left(T_{\text {ann }}>320\right.$ K).

The time resolution of the lifetime spectrometer was determined by measuring perfect Mo and Si samples and analyzing the lifetime spectra with the FORTRAN program RESOLUTION. ${ }^{21}$ The resolution function was found to be a one-component Gaussian function with a full width at half maximum (FWHM) of 217 ps. Also the contributions of the Havar foil and of the ${ }^{22} \mathrm{NaCl}$ salt were obtained by the program. The total intensity of the source components was found to be $16 \%$ with lifetimes of $170 \mathrm{ps}(13.5 \%)$ and $450 \mathrm{ps}(2.5 \%)$. The lifetime data were analyzed with the FORTRAN program POSITRONFIT ${ }^{21}$ by using this resolution function and these source components.

The 12-MeV proton irradiations were performed from both sides of the sample set to obtain a homogeneous defect distribution. The penetration depth and the longitudinal straggling of $12-\mathrm{MeV}$ protons in $\mathrm{Si}$ are 950 and 15 $\mu \mathrm{m}$, respectively, ${ }^{22}$ hence all protons penetrated the total sample set. The samples were packed with indium to maximize the heat transfer from the samples to the cold head. The current of the proton beam was kept low $(\sim 6$ $\mathrm{nA}$ ) in order to keep the sample temperature below $20 \mathrm{~K}$. In the first irradiation (Si-I) the samples were irradiated at $15 \mathrm{~K}$ to a dose of $2.4 \times 10^{13}$ protons $/ \mathrm{cm}^{2}$. These samples were then annealed isochronally up to $150 \mathrm{~K}$ in $10-\mathrm{K}$ steps, after which the temperature dependence of the specific trapping rate of positrons was studied by measuring the positron-lifetime spectra at temperatures between 15 and $140 \mathrm{~K}$. Then the sample set was further irradiated at $15 \mathrm{~K}$ to a total dose of $2.3 \times 10^{14} \mathrm{p} / \mathrm{cm}^{2}$ (Si-II). A third proton irradiation (Si-III) to a total dose of $3.0 \times 10^{13}$ $\mathrm{p} / \mathrm{cm}^{2}$ was performed on another sample set.

In the analysis of the positron-lifetime spectra a lifetime component of about $1.5 \mathrm{~ns}$ was found. The intensity of this lifetime component was about $0.05 \%$ in the lessirradiated samples and about $0.1 \%$ in the heavily irradiated $\mathrm{Si}$. We therefore fixed $\tau_{3}$ to $1.5 \mathrm{~ns}$ and $I_{3}$ either to $0.05 \%$ (Si-I and $\mathrm{Si}-\mathrm{III}$ ) or to $0.1 \%$ (Si-II). This component is probably due to orthopositronium that annihilated in the bulk or on the surfaces of the Si samples. The variances of the fits were between 1.0 and 1.2 for most spectra.

\section{RESULTS AND DISCUSSIONS}

\section{A. As irradiated}

The positron lifetime in the perfect Si crystal was measured prior to the irradiations, and a lifetime of $217 \pm 1$ ps was found at $15 \mathrm{~K}$. This is in excellent agreement with the earlier reported value of $218 \mathrm{ps}^{23-25}$ The calculated positron lifetime of Puska et al. is 219 ps. $^{26}$

The Si samples were irradiated at $15 \mathrm{~K}$ with $12-\mathrm{MeV}$ protons to a dose of $2.4 \times 10^{13} \mathrm{p} / \mathrm{cm}^{2}(\mathrm{Si}-\mathrm{I})$. The samples were then annealed in $10-\mathrm{K}$ steps with an annealing rate of $25 \mathrm{~K} / \mathrm{h}$. All positron-lifetime spectra were measured at $15 \mathrm{~K}$. After the irradiation two lifetime components could clearly be detected. The longer lifetime was $273 \pm 6$ ps which is in good agreement with the experimentally suggested monovacancy lifetimes of $270-275$ ps in $\mathrm{Si}^{27-29}$ Also the calculated positron lifetime of $270 \mathrm{ps}$ (Ref. 12) in a neutral Si monovacancy with a realistic breathing-mode relaxation $(4.2 \%$ outwards) is close to our experimental result. The intensity of $50 \pm 7 \%$ of the defect-related component is high when compared to the irradiation dose. This indicates that positrons trap very effectively to the defects produced in the samples. The specific positron-trapping rate to negatively charged vacancies in Si has recently been estimated to be as high as $10^{17}-10^{18} \mathrm{~s}^{-1}$ at low temperatures, ${ }^{27}$ whereas for neutral vacancies this value has been estimated to be only of the order of $10^{15} \mathrm{~s}^{-1} .^{18}$ Thus, we conclude that the samples contained negatively charged monovacancies.

The Si-I samples were annealed up to $150 \mathrm{~K}$, after which the temperature dependence of the positronlifetime parameters was studied by measuring positronlifetime spectra at temperatures from 15 to $140 \mathrm{~K}$. These results will be discussed in Sec. III C.

The sample set was further irradiated at $15 \mathrm{~K}$ with 12 $\mathrm{MeV}$ protons to a total dose of $2.3 \times 10^{14} \mathrm{p} / \mathrm{cm}^{2}$ (Si-II). Isochronal annealings were carried out from 15 to $320 \mathrm{~K}$ in $10-\mathrm{K}$ steps and above $320 \mathrm{~K}$ in 20 - or $50-\mathrm{K}$ steps. After the irradiation two lifetimes, in addition to the fixed long lifetime $\tau_{3}$, were detected: $\tau_{2}=277 \pm 4 \mathrm{ps}$, cor- 
responding to positrons that annihilated in monovacancies, and $\tau_{1}=131 \pm 9 \mathrm{ps}$, which is the modified bulk lifetime (Fig. 1). The intensity of the $\tau_{2}$ component, $I_{2}$, was higher than $75 \%$ after the irradiation (see Fig. 2). This intensity stays constant up to annealing temperatures of about $150 \mathrm{~K}$, after which it decreases almost linearly, within statistics, to become zero at $600 \mathrm{~K}$. The corresponding positron lifetime remains at about 275 ps in the whole annealing temperature range, which means that (i) either the defects remain the same but decrease in number above $150 \mathrm{~K}$, or that (ii) new defects, created when the primary defects migrate above $150 \mathrm{~K}$ and get trapped by impurities, give rise to similar positron lifetimes as the primary defects. We shall later in this chapter argue that the secondary defects are negatively charged complexes of a $\mathrm{Si}$ monovacancy and a nearest-neighbor substitutional oxygen atom, $\mathrm{V}_{2} \mathrm{O}^{-}$, and our calculations indeed yield that the positron lifetime is almost identical in pure monovacancies and in these $V_{2} \mathrm{O}^{-}$pairs.

When high-energy protons are used in irradiations, the possibility of creating divacancies in addition to monovacancies must be considered. This is due to the large displacement cascades created by the protons. The experimental positron-lifetime value for divacancies in $\mathrm{Si}$ is about 320 ps. $^{23,28,30}$ We tried to analyze our positronlifetime spectra by fixing $\tau_{2}$ to 270 ps and $\tau_{3}$ to 320 ps and by searching for the modified bulk lifetime $\tau_{1}$ and for the intensities $I_{1}, I_{2}$, and $I_{3}$ in order to see if divacancies, besides monovacancies, were present in the samples. No systematic behavior could be seen in the intensities of $\tau_{2}$ and $\tau_{3}: I_{2}$ had values from $46 \%$ to $110 \%$ with no de-

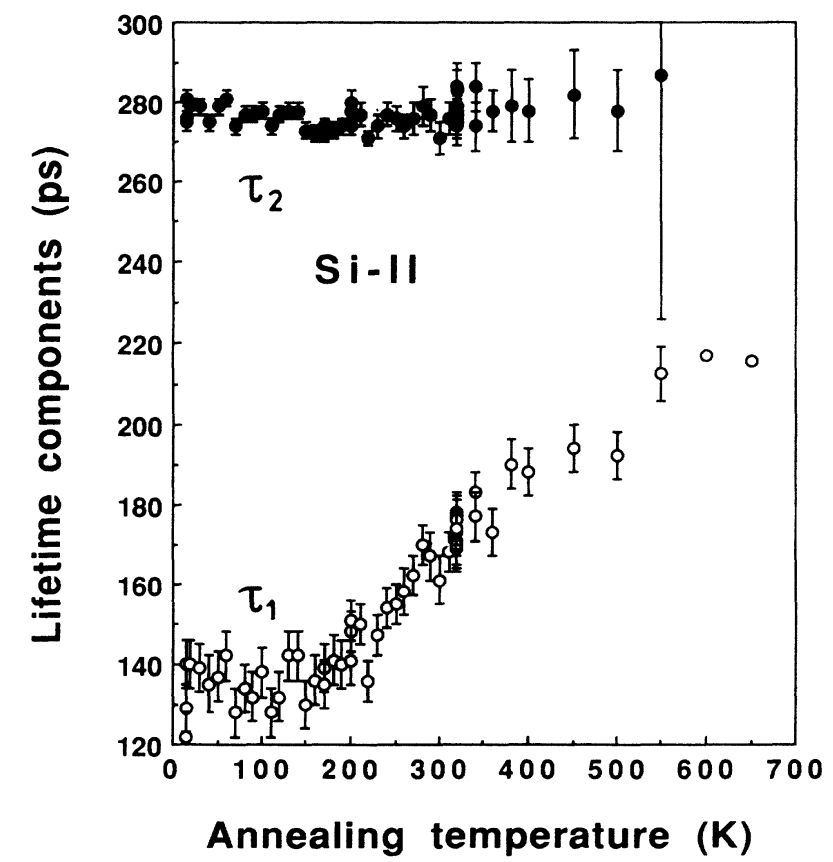

FIG. 1. The positron-lifetime components for the protonirradiated Si. The irradiation dose was $2.3 \times 10^{14}$ protons $/ \mathrm{cm}^{2}$ (Si-II) and the lifetime spectra were measured at $15 \mathrm{~K}$. The irradiations were also carried out at $15 \mathrm{~K}$.

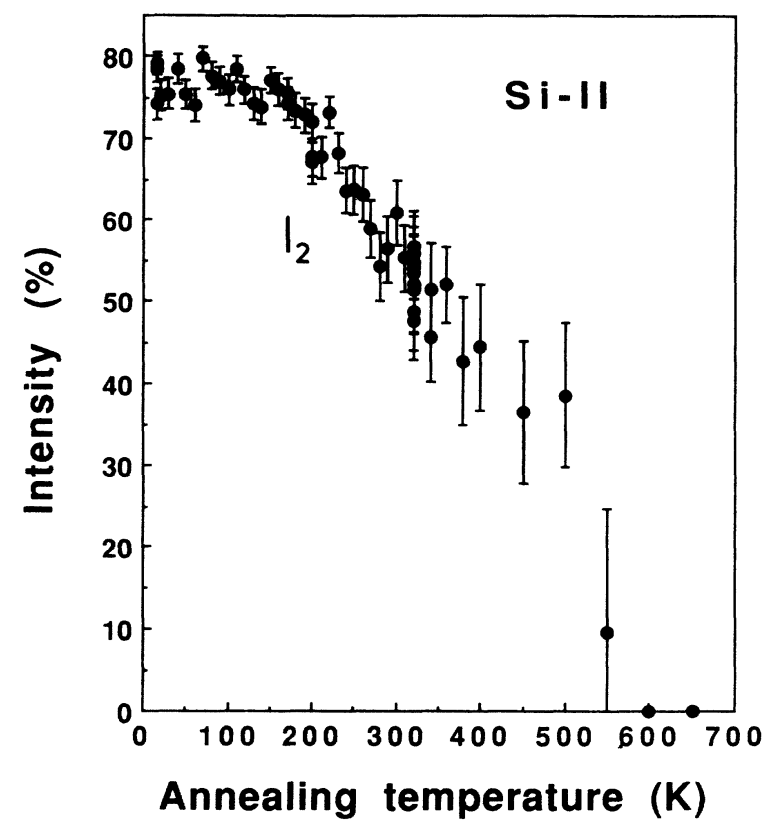

FIG. 2. The intensity of the defect-related lifetime $\left(\tau_{2}\right)$ in proton-irradiated Si-II.

creasing trend, and $I_{3}$ fluctuated randomly between $-19 \%$ and $11 \%$. We therefore believe that the number of divacancies was negligible in the samples, and that the results can be understood by assuming only a single-trap state. The validity of this assumption was investigated by using the one-trap model. ${ }^{31}$ In this model the bulk lifetime is calculated as

$$
\tau_{b}=\left(\sum_{i=1}^{2} \frac{I_{i}}{\tau_{i}}\right)^{-1}
$$

As can be seen from Fig. 3, the model gives reasonable results for $\tau_{b}$ (the measured bulk lifetime is $217 \mathrm{ps}$ ). This supports the idea that the Si-II samples consisted only of monovacancy-type defects. The situation is not totally clear if the charge state of monovacancies was negative and that of divacancies was neutral. In this case positrons would have gotten trapped much more effectively by monovacancies than by divacancies, and the intensity of the 320-ps-lifetime component would therefore have been extremely low.

\section{B. Annealing behavior}

The average positron lifetime, or the statistical mean of the positron-lifetime distribution, is defined as

$$
\bar{\tau}=\sum_{i=1}^{N} I_{i} \tau_{i},
$$

where $N$ is the number of lifetime components, $\tau_{i}$ is a positron-lifetime component, and $I_{i}$ is the corresponding intensity. The values of $\bar{\tau}$ for the Si-II experiment are shown in Fig. 3 as a function of annealing temperature. Two clear annealing steps can be seen. The first step 


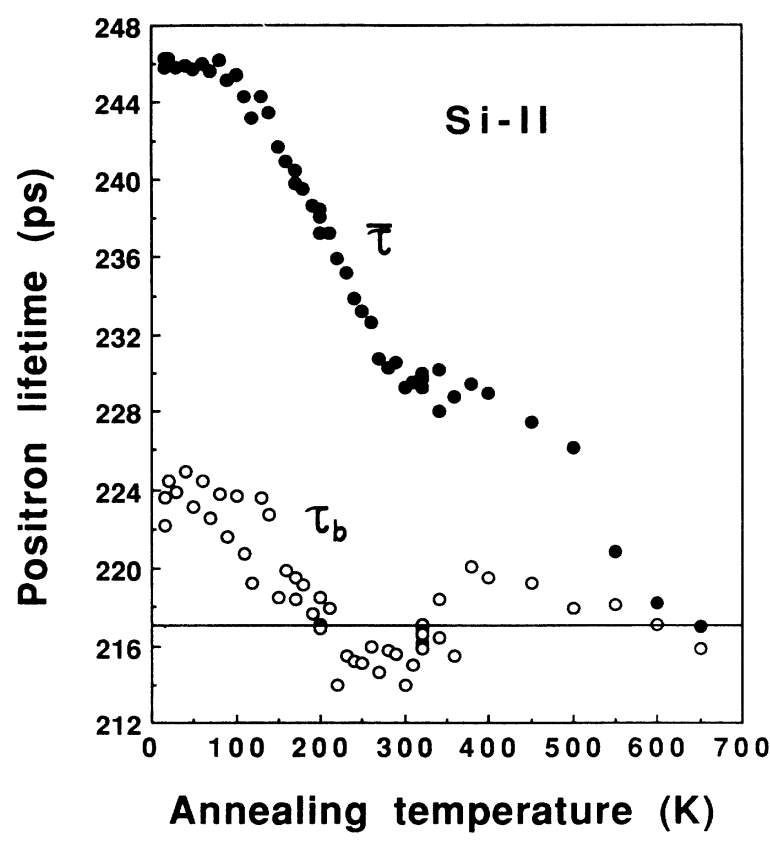

FIG. 3. The mean positron lifetime $\bar{\tau}$ (solid circles) and the bulk lifetime $\tau_{b}$ calculated by the one-trap model (open circles) as a function of annealing temperature. The lifetime spectra were measured at $15 \mathrm{~K}$ and the Si samples were irradiated at 15 $\mathrm{K}$ with $12-\mathrm{MeV}$ protons to a dose of $2.3 \times 10^{14}$ protons $/ \mathrm{cm}^{2}$ (SiII). The line indicates the measured bulk lifetime of $217 \mathrm{ps}$.

starts at about $100 \mathrm{~K}$ and continues until $300 \mathrm{~K}$. This step was also detected in the Si-I experiment, although the annealings were then performed only up to $150 \mathrm{~K}$. Note that the onset of this stage is seen at $150 \mathrm{~K}$ in the two-component analysis (see Figs. 1 and 2). This is probably due to the fluctuations in the analysis. The average lifetime is less sensitive to small fluctuations and thus more reliable (but less informative). Kimerling et al. have studied the annealing kinetics of $\mathrm{Si}$ by the EPR technique and found that in FZ Si, $E 2$ centers start to anneal out at $120 \mathrm{~K} .{ }^{17}$ The $E 2$ center is proposed to correspond to the negatively charged monovacancy. ${ }^{17}$ According to EPR and DLTS studies of Watkins et al. the doubly negative monovacancy in Si starts to anneal out at about $70 \mathrm{~K}$, and the neutral monovacancy at about 210 $\mathrm{K} .{ }^{32}$ We thus conclude that our samples consisted mainly of singly negative monovacancies which started to anneal out at about $100 \mathrm{~K}$.

This first annealing stage is rather long. It thus seems that free, negatively charged monovacancies annealed out slowly at temperatures between 100 and $300 \mathrm{~K}$. A similar annealing stage has also been observed in electronirradiated Si by the Doppler-broadening measurements of Fuhs et al. ${ }^{23}$ This long annealing stage might be due to weak trapping of the migrating monovacancies by some impurity atoms. Another possibility for this long stage might be that the negative vacancies annealed out at the range of 100 to about $200 \mathrm{~K}$, after which the Fermi level decreased below a certain level in the band gap $^{24}$ and the vacancies became neutral, continuing to anneal out from
$200 \mathrm{~K}$ (Ref. 32) to $300 \mathrm{~K}$. Theoretical calculations have shown that if atomic relaxation is omitted, the positron lifetime in $V^{-}$is almost the same as that in $V^{0} .{ }^{12,33}$ Also, experimental results indicate no difference in positron lifetimes at $V^{-}$and $V^{0}$. However, the specific positrontrapping rate to neutral vacancies in $\mathrm{Si}$ is believed to be about 100-1000 times smaller than that to negatively charged vacancies. ${ }^{18,27}$ If the latter assumption was correct, even though it is hard to find any reason why the Fermi level would have moved to such a low position ${ }^{24}$ in the gap, we should therefore have seen a strong decrease in $I_{2}$ at the transition region. The values of $I_{2}$ did not show this kind of behavior: $I_{2}$ decreased smoothly from $75 \%$ to zero at temperatures between 150 and $600 \mathrm{~K}$ (see Fig. 2).

It could also be possible that free, negatively charged monovacancies annealed out rather fast above $100 \mathrm{~K}$, after which some vacancy-impurity pairs started to dissociate. The EPR and DLTS studies ${ }^{32}$ of Watkins et al. show that at the temperature range of 100 to $300 \mathrm{~K}$ only monovacancy pairs with boron and germanium could migrate in $\mathrm{Si}$, in addition to free monovacancies. However, the existence of these complexes can most probably be excluded because the samples should not contain Ge and the concentration of $B$ was very low $\left(\sim 2 \times 10^{-5} \mathrm{ppm}\right)$.

Oxygen and carbon were the most significant impurities in the samples. The presence of complexes of a substitutional oxygen atom and a nearest-neighbor Si monovacancy, $V_{2} \mathrm{O},{ }^{34}$ could therefore be possible. Lee et al. have reported that neutral $V_{2} \mathrm{O}$ complexes start to anneal only at about $620 \mathrm{~K}$ (Ref. 34), which strongly suggests that even the negatively charged $V_{2} \mathrm{O}$ defects do not anneal at temperatures below $300 \mathrm{~K}$. One cannot rule out the possibility of forming $V$-C complexes during the vacancy migration but the role of carbon on the defect recovery is not known. Our conclusion is that free, singly negatively charged $\mathrm{Si}$ monovacancies annealed out slowly at temperatures between 100 and $300 \mathrm{~K}$.

The second annealing step begins at about $400 \mathrm{~K}$ (see Fig. 3). One could suggest that this annealing stage is due to migration of divacancies which might have grown by agglomeration of migrating monovacancies above 100 $\mathrm{K}$. However, divacancies in $\mathrm{Si}$ are known to become mobile only at about $550 \mathrm{~K}$ (Refs. 32 and 35) and, as discussed earlier in this chapter, we do not believe that the samples did contain a detectable amount of divacancies. Another possibility for explaining this step could be the annealing of $\mathrm{V} \cdot \mathrm{P}$ pairs ${ }^{12,36}$ as they have been observed to anneal out at about $400 \mathrm{~K} \cdot{ }^{32,37}$ However, the concentration of phosphorus was so small in the samples that $V \cdot P$ complexes were most probably out of our detection limit. Also the experimentally observed positron lifetime in the $V \cdot P$ defect is against the existence of these pairs: the measured values are in the range of $248-255$ ps (Refs. 27 and 29), clearly shorter than $\tau_{2}$ in our experiments. It therefore seems that the annealing step above $400 \mathrm{~K}$ shall be explained by annealing out of $V_{2} \mathrm{O}$ complexes that were created during the first annealing stage between 100 and $300 \mathrm{~K}$, when migrating monovacancies were trapped by "substitutional" oxygen atoms ( $A$ centers). ${ }^{4}$

The annealing of neutral $V_{2} \mathrm{O}$ complexes have been 
suggested to start at about $620 \mathrm{~K} .{ }^{34}$ On the other hand, our studies on the temperature dependence of the specific trapping rate of positrons (see Sec. III C) indicate that the charge state of the main positron traps was negative even after annealing at $300 \mathrm{~K}$. If the samples did contain $V_{2} \mathrm{O}$ defects at $400 \mathrm{~K}$, their charge state would therefore have been negative. We calculated the positron wave function and annihilation characteristics for the case where one of the nonrelaxed nearest-neighbor $\mathrm{Si}$ atoms around a vacancy was replaced by an oxygen atom (the $V_{2} \mathrm{O}$ complex) by using the method of Puska and Nieminen. ${ }^{38,39}$ The wave function was strongly localized at the vacancy, and the positron lifetime was only 2 ps shorter than that for a free monovacancy. The lifetime components corresponding to these two defects are thus not distinguishable in experiments. Since the value of $\tau_{2}$ did not change significantly from the monovacancy lifetime after the first annealing step (see Fig. 1), it is possible that $V_{2} \mathrm{O}^{-}$complexes were created in this step, and that these defects are then those that annealed out above $400 \mathrm{~K}$.

The third proton irradiation (Si-III) was also performed with 12-MeV protons, but this time the dose was only about $3.0 \times 10^{13} \mathrm{p} / \mathrm{cm}^{2}$, i.e., a factor of 10 smaller than that for Si-II. Now the main interest was to compare the annealing behavior in these two experiments. The 100-300-K annealing step was clearly detected also in the Si-III samples: the mean lifetime decreased linearly from 224 to $218 \mathrm{ps,} \mathrm{i.e.,} \mathrm{the} \mathrm{bulk} \mathrm{positron} \mathrm{lifetime} \mathrm{was}$ reached after annealing at $300 \mathrm{~K}$ and therefore no further annealing stage could be seen. The vacancy concentration was probably too low to produce a detectable amount of monovacancy-oxygen pairs in the samples. The value of the long-lifetime component was, within uncertainties, the same $(271 \pm 11 \mathrm{ps})$ as that in the Si-I and in the Si-II samples.

\section{Trapping of positrons}

The trapping rate of positrons to a lattice defect, $\kappa$, is written as

$$
\kappa=\mu_{+} c_{v},
$$

where $\mu_{+}$is the specific trapping rate of positrons to the defect in question, and $c_{v}$ is the defect concentration. In the one-trap model $^{31} \kappa$ is given as

$$
\kappa=\frac{\bar{\tau}-\tau_{b}}{\tau_{d}-\bar{\tau}} \lambda_{b},
$$

where $\tau_{d}$ is the defect-related lifetime $\left(\tau_{2}\right), \tau_{b}$ is the bulk lifetime, and $\lambda_{b}$ is the positron-annihilation rate in the perfect crystal $\left(=\tau_{b}^{-1}\right)$. The temperature dependence of $\kappa$ was studied by measuring positron-lifetime spectra at different temperatures after the samples were annealed at a certain higher temperature and by using the one-trap model [Eq. (4)]. In this way every lifetime spectrum corresponded to the same concentration of vacancies, i.e., $c_{v}$ was constant in Eq. (3). Thus, the temperature dependence of $\kappa$ gave the temperature dependence of the specific positron-trapping rate for the defect.

The assumption that the samples consisted only of one type of defect was most reasonable for the $\mathrm{Si}$-I and $\mathrm{Si}$-III samples where the irradiation doses were low. After the Si-I samples were annealed at $150 \mathrm{~K}$, the positronlifetime spectra were measured at the temperature range of 15 to $140 \mathrm{~K}$. The mean lifetime $\bar{\tau}$ calculated by Eq. (2) is plotted in Fig. 4 as a function of measuring temperature. As can be seen, $\bar{\tau}$ decreases very strongly as the temperature rises. The trapping rate values were calculated for these results by fixing $\tau_{2}$ to its average value in the spectra in question, and by using Eq. (4). In the calculations 217 ps was used for the bulk lifetime. Naturally, also the temperature dependence of $\kappa$ (see Fig. 5) is qualitatively the same as that for $\bar{\tau}$.

The trapping of positrons to a negatively charged vacancy is believed to go either through direct electron-hole excitations or through Rydberg states at the Coulomb tail of the vacancy, ${ }^{18,27}$ leading to huge positron-trapping probabilities. These Rydberg states are assumed to be shallow traps for positrons, and the detrapping of positrons from these states should therefore be possible at high temperatures. From this, and by using the twostage capture model of Gibb et al. ${ }^{40}$ the experimentally observed temperature dependence of the specific positron trapping rate to $V^{-}$in Si has recently been suggested to follow an $e^{E / k T}$ law above $60 \mathrm{~K} .{ }^{27}$ Here $E$ is the binding energy of a positron to this shallow Rydberg-state trap, and a value of $20 \pm 2 \mathrm{meV}$ has been proposed for $V^{-} .^{27}$ We have plotted the logarithm of $\kappa$ as a function of $1 / T$ for the points in Fig. 5 (see Fig. 6) in order to check the $e^{E / k T}$ dependence. Although a line could somehow be drawn through the points corresponding to temperatures above $\sim 60 \mathrm{~K}$, no strong evidence about this kind of temperature dependence can be seen.

The temperature dependence of $\mu_{+}$to negatively charged vacancies in $\mathrm{Si}$ has often been studied by using Lax's calculations ${ }^{41}$ about the trapping of electrons and

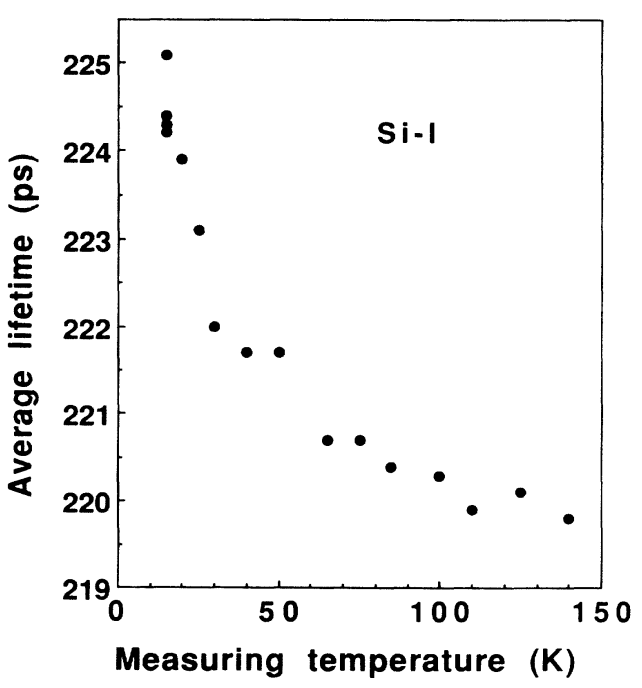

FIG. 4. The mean positron lifetime as a function of measuring temperature. The samples were irradiated with $12-\mathrm{MeV}$ protons to a dose of $2.4 \times 10^{13}$ protons $/ \mathrm{cm}^{2}$ (Si-I) and the samples were annealed at $150 \mathrm{~K}$ before the measurements. 


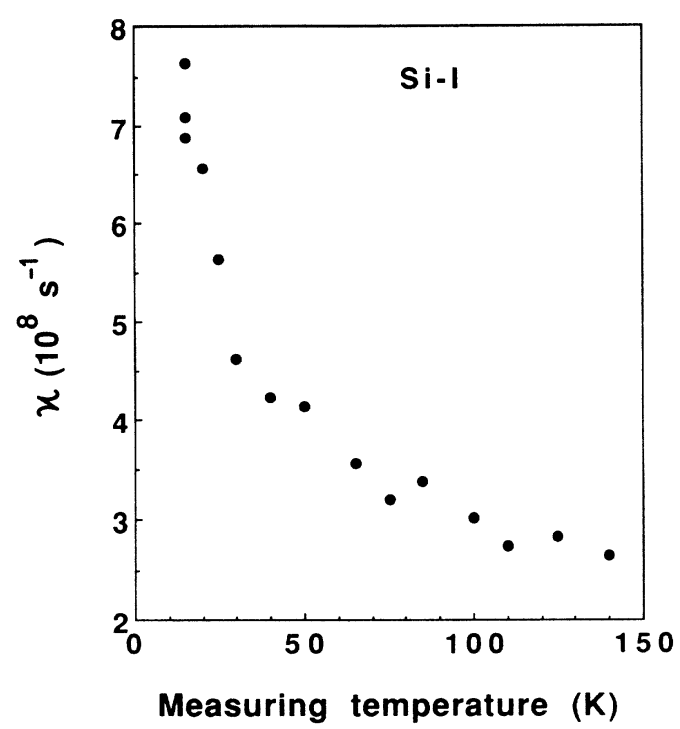

FIG. 5. The trapping rate of positrons vs temperature. $\kappa$ is calculated by using the one-trap model and the data in Fig. 4.

holes by charged defects. Positrons are first thought to be captured in a highly excited state, a shallow positron trap with the binding energy of about $k T$. Thereafter, positrons are thought to lose their energy by phonon emission until they reach the ground state. If positrons get trapped at negatively charged vacancies by emission of optical phonons, $\mu_{+}$should be proportional to $T^{0.5-n}$, where $n$ is 1 at low temperatures and 4 at high temperatures. On the other hand, if the trapping goes through acoustic phonons, $\mu_{+}$should vary as $T^{-1}$. According to Lax, the acoustic-phonon contribution predominate at low temperatures and optical phonons are important only at room temperature. ${ }^{41}$ Dannefaer et al. have found that

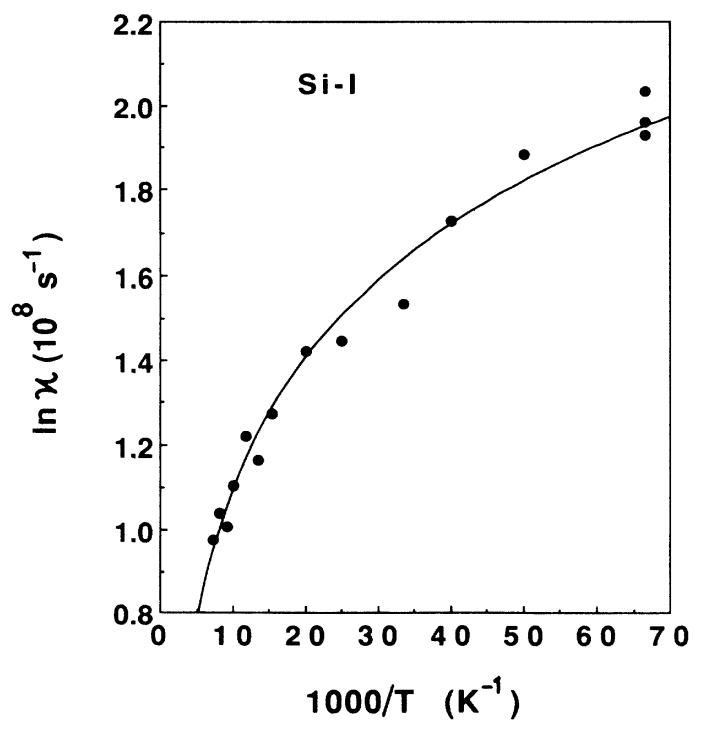

FIG. 6. Natural logarithm of $\kappa$ as a function of $1 / T$ for the data in Fig. 5. The line shows the behavior corresponding to the $T^{-0.5}$ dependence. for negatively charged divacancies, $V_{2}^{-}$, in $p$-type single crystal $\mathrm{Si}, \mu_{+}$is proportional to $T^{-0.5}$ at temperatures below $40 \mathrm{~K}$ (Ref. 42) and that at temperatures above 40 $\mathrm{K}, \mu_{+}$varies as $T^{-3.5}$ (Ref. 42) or as $T^{-2} \cdot{ }^{28}$ Mascher et al. have recently reported that for $V_{2}^{-}$in slightly $n$ type Czochralski-grown $\mathrm{Si}, \mu_{+}$has a $T^{-2}$-dependence. ${ }^{43}$ Moreover, Brandt et al. ${ }^{44}$ and Fuhs et al. ${ }^{45}$ have reported that $\mu_{+}$varies as $T^{-1.5}$ for these defects. The positron-lifetime results of Mäkinen et al. ${ }^{27}$ for $V^{-}$in $n$ type FZ Si can also be explained by assuming a $T^{-2.6}$ dependence in $\mu_{+}$at temperatures between 60 and $120 \mathrm{~K}$.

In the light of the results discussed above, we assume that $\mu_{+}$is proportional to $T^{-n}$ for the negative vacancytype defects $V^{-}$and $V_{2} \mathrm{O}^{-}$in our $\mathrm{Si}$ samples. If the vacancy concentration is assumed to be constant after the $150-\mathrm{K}$ annealing, the temperature dependence of $\kappa$ directly gives the temperature dependence of $\mu_{+}$. We plotted $\ln \kappa$ as a function of $\ln T$ for the points in Fig. 5 and made a least-squares fit to the data in order to find the value of the exponent from the slope of the line. A value of about -0.5 was found. Also, in other measurements for the temperature dependence of $\mu_{+}\left(\mathrm{Si}-\mathrm{I}, T_{\text {ann }}=150 \mathrm{~K}\right.$; Si-II, $T_{\text {ann }}=150$ and $300 \mathrm{~K}$; Si-III, $T_{\text {ann }}=90$ and $200 \mathrm{~K}$ ), which will be discussed later in this chapter, the same value was obtained. This means that the specific trapping rate of positrons to $V^{-}$and to $V_{2} \mathrm{O}^{-}$is proportional to $T^{-0.5}$. This can clearly be seen in Fig. 7, where the measured $\kappa$ is plotted as a function of $T^{-0.5}$ for the points corresponding to the $\mathrm{Si}-\mathrm{I}$ samples after annealing at $150 \mathrm{~K}$.

Also, Puska et al. have recently derived theoretically that in the case of negatively charged vacancies in $\mathrm{Si} \mu_{+}$ is proportional to $T^{-0.5} \cdot{ }^{18}$ This decreasing trend is a result of the Coulomb-wave behavior of the initial positron wave function: the amplitude of the wave function increases strongly at the vacancy when its energy eigenvalue decreases. Our results agree very well with this model.

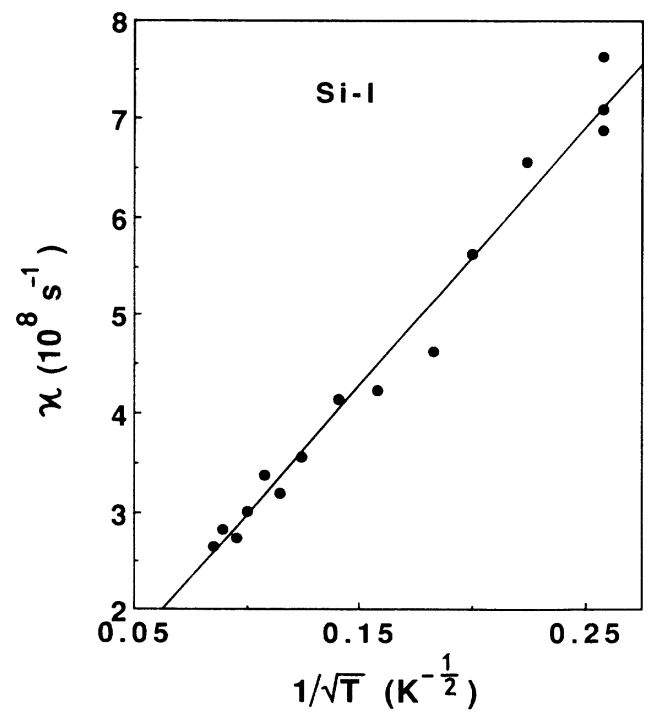

FIG. 7. The trapping rate of positrons as a function of $1 / \sqrt{T}$ for the points in Fig. 5. The line corresponds to a least-squares fit to the data. 
This confirms our suggestion that the monovacancies in our samples were negatively charged, and that no detrapping took place as the temperature dependence can be understood by assuming only trapping.

We also calculated how $\ln \kappa$ should behave as a function of $1 / T$ if the $T^{-0.5}$ dependence was correct. If the trapping rate is written as

$$
\kappa=\kappa_{0}+A \frac{1}{\sqrt{T}},
$$

we get that

$$
\ln \kappa=\ln \left(\frac{A+\kappa_{0} \sqrt{T}}{\sqrt{1000}}\right)+\frac{1}{2} \ln \left(\frac{1000}{T}\right) .
$$

The resulting curve is drawn in Fig. 6, and it fits very well in the data points. Here $\kappa_{0}$ is the high-temperature limit of the positron trapping rate, and it should therefore be zero. $A$ is related to the number of defects giving the $T^{-0.5}$ dependence in $\kappa$, i.e., $A$ is proportional to the concentration of $V^{-}$and $V_{2} \mathrm{O}^{-}$. For the Si-II samples the value of $A$ decreased from about 122 to 40 (in units of $10^{8}$ $\mathrm{K}^{1 / 2} / \mathrm{s}$ ) as the annealing temperature went from 150 to $300 \mathrm{~K}$, and for the Si-III samples $A$ was about 31 after annealing at $90 \mathrm{~K}$, decreasing to a value of about 12 (in the same units) after annealing at $200 \mathrm{~K}$.

We measured the temperature dependence of $\kappa$ also for the Si-III samples after annealing at 90 and $200 \mathrm{~K}$. These results also clearly agree with the $T^{-0.5}$ dependence for $\kappa$ (and $\mu_{+}$). We did the same for the Si-II samples after annealing at 150 and $300 \mathrm{~K}$ and, again, the results strongly support the $T^{-0.5}$ dependence. These results are shown in Fig. 8 together with the results for the Si-I experiment.

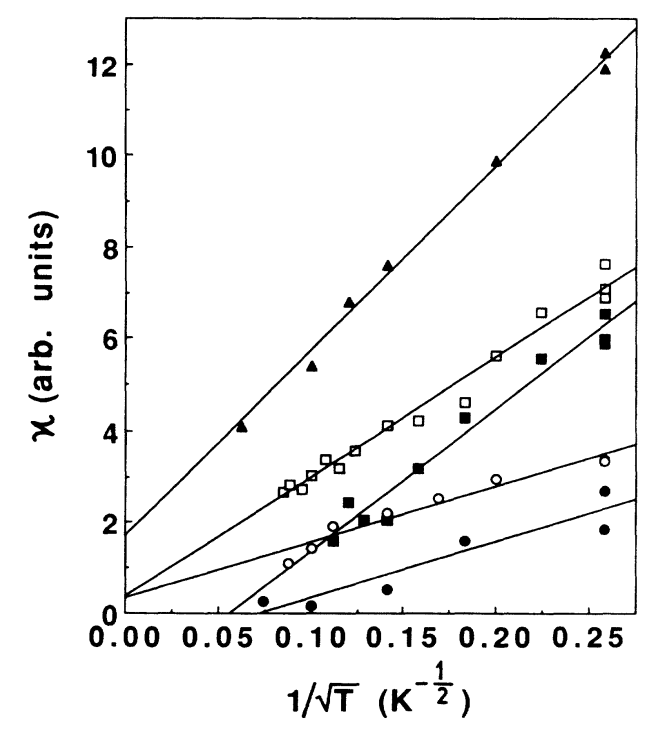

FIG. 8. Same as Fig. 7 but for the proton-irradiated samples annealed at $90 \mathrm{~K}$ (Si-III, solid squares), $150 \mathrm{~K}$ (Si-I, open squares; Si-II, open circles), $200 \mathrm{~K}$ (Si-III, solid circles), and 300 $\mathrm{K}$ (Si-II, solid triangles).
All data points are nicely described by straight lines. The values of $\kappa$ are not fully comparable in Fig. 8, and they should only be taken as a proof of the $T^{-0.5}$ law. It should be noted that the same temperature dependence is seen also after annealing at $300 \mathrm{~K}$, where the $V^{-}$defects had already disappeared. This means that the temperature dependence of $\mu_{+}$for $V_{2} \mathrm{O}^{-}$complexes is the same as that for $V^{-}$.

If the trapping of positrons was assumed to be diffusion limited, $\mu_{+}$would vary as $D_{+}(T) T^{-1}$, where $D_{+}$is the diffusion constant. ${ }^{46}$ As $D_{+}$is proportional to $T^{-0.5}$ (Ref. 46), the specific positron-trapping rate would be proportional to $T^{-1.5}$. This was not observed, and we conclude that the positron trapping was only transition limited. Also, the measuring temperatures were so low that the presence of phonons limiting the diffusion of positrons was not probable.

It is interesting to note that $\kappa_{0}$ is not equal to zero for the cases in Fig. 8, i.e., the trapping rate does not go to zero at the high-temperature limit. This could indicate that our samples included also neutral vacancy-type traps in addition to the negatively charged monovacancy-type traps $V^{-}$and $V_{2} \mathrm{O}^{-}$. Other possibilities are that the $T^{-0.5}$ behavior is not exactly valid for the defects in question or that the values of $\kappa$ are somewhat inaccurate. The last assumption is reasonable, because $\kappa_{0}$ could be made to be zero by changing the value of $\tau_{b}$ by only $1-3$ ps in Eq. (4). These small changes had almost no effect on the values of $A$ in Eq. (5) and on the variances of the linear fits to the data points, which again supports the $T^{-0.5}$ dependence of $\mu_{+}$.

In principle, the monovacancy concentration can be estimated by using Eq. (3) and the one-trap model for $\kappa$ [Eq. (4)]. The problem is that the value of the specific trapping rate $\mu_{+}$is not known. In the model calculations of Puska et al. ${ }^{18}$ the value of $\mu_{+}$is estimated to be of the order of $10^{16} \mathrm{~s}^{-1}$ for positrons that trap to a negatively charged vacancy through direct electron-hole excitations at about $10-20 \mathrm{~K}$. If the trapping goes through $\mathrm{Rydberg}$ states this value can be much higher. If $\mu_{+}$is roughly estimated to be $10^{16} \mathrm{~s}^{-1}$ at $15 \mathrm{~K}$, the upper limit of the monovacancy concentration is $0.05 \mathrm{ppm}$ for the Si-III samples after the irradiation. The relatively high irradiation dose used in the Si-II experiment results in a maximum vacancy concentration of about $0.4 \mathrm{ppm}$. These results correspond to a maximum effective vacancy production rate of about four vacancies per proton during its path through the specimens. The number of atomic displacements ought to be considerably higher. The reason for the low vacancy production is the high mobility of the interstitial $\mathrm{Si}$ atoms at the irradiation temperature of 15 $\mathrm{K}$ (even at $1.5 \mathrm{~K}$ ), ${ }^{47}$ so that the irradiation-induced Frenkel pairs annihilated very effectively.

\section{CONCLUSIONS}

High-purity single-crystal Si samples were irradiated at $15 \mathrm{~K}$ with $12-\mathrm{MeV}$ protons, and the annealing of the created vacancies was studied by the positron-lifetime 
method. A strong annealing stage was seen between 100 and $300 \mathrm{~K}$. It is connected to the migration of free, singly negatively charged monovacancies. From 300 to 400 $\mathrm{K}$ the vacancy concentration was almost unchanged. The second annealing stage between 400 and $600 \mathrm{~K}$ is, tentatively, suggested to be due to annealing out of negatively charged complexes of a $\mathrm{Si}$ monovacancy and a nearest-neighbor substitutional oxygen atom $\left(\mathrm{V}_{2} \mathrm{O}^{-}\right)$.

The temperature dependence of the specific positron trapping rate $\mu_{+}$to $V^{-}$and to $V_{2} \mathrm{O}^{-}$was studied in the range of 15 to $280 \mathrm{~K}$, and at these temperatures a $T^{-0.5}$ dependence was clearly observed.

\section{ACKNOWLEDGMENTS}

The authors want to thank M. Manninen, M. J. Puska, P. Hautojärvi, and J. Mäkinen for many helpful discussions. We are also grateful to T. Visler at Topsil Semiconductor Materials a/s for the Si samples and for the impurity analysis. One of us (S.M.) wants to thank the Emil Aaltonen Foundation for financial support.
"Present address: Outokumpu Poricopper Oy, P. O. Box 60, SF-28101 Pori, Finland.

${ }^{1}$ R. C. Newman, Rep. Prog. Phys. 45, 1163 (1982).

${ }^{2}$ Proceedings of the 14 International Conference on Defects in Semiconductors, Paris, 1986, edited by H. J. von Bardeleben (Materials Science Forum, Aedermannsdorf, Switz., 1986), Vols. 10-12.

${ }^{3}$ M. Lannoo and J. Bourgoin, Point Defects in Semiconductors I, Vol. 22 of Springer Series in Solid-State Sciences, edited by M. Cardona (Springer-Verlag, Heidelberg, 1981); J. Bourgoin and M. Lannoo, Points Defects in Semiconductors II, Vol. 35 of Springer Series in Solid-State Sciences, edited by M. Cardona (Springer-Verlag, Heidelberg, 1983).

${ }^{4}$ G. D. Watkins and J. W. Corbett, Phys. Rev. 121, 1001 (1961); 134, A1359 (1964); 138, A543 (1965).

${ }^{5}$ R. C. Newman, Infrared Studies of Crystal Defects (Taylor and Francis, Paris, 1973).

${ }^{6}$ C. T. Sah, L. Forbes, L. L. Rosier, and A. F. Tasch, Solid State Electron. 13, 759 (1970).

${ }^{7}$ D. V. Lang, J. Appl. Phys. 45, 3014 (1974).

${ }^{8}$ See, e.g., in Defects in Crystals, Proceedings of the 7th International School at Szczyrk, Poland, 1985, edited by E. Mizera (World Scientific, Singapore, 1987).

${ }^{9}$ Positrons in Solids, Vol. 12 of Topics in Current Physics, edited by P. Hautojärvi (Springer, Heidelberg, 1979).

${ }^{10}$ Positron Solid State Physics, Proceedings of the International School of Physics "Enrico Fermi," Course LXXXIII, Varenna, 1981, edited by W. Brandt and A. Dupasquier (NorthHolland, Amsterdam, 1983).

${ }^{11}$ Microscopic Methods in Metals, Vol. 40 of Topics in Current Physics, edited by U. Gonser (Springer-Verlag, Berlin, 1986).

${ }^{12}$ S. Mäkinen and M. J. Puska, Phys. Rev. B 40, 12523 (1989).

${ }^{13}$ S. Dannefaer, P. Mascher, and D. Kerr, J. Phys. Condens. Matter 1, 3213 (1989).

${ }^{14}$ G. D. Watkins and J. R. Troxell, Phys. Rev. Lett. 44, 593 (1980).

${ }^{15}$ G. A. Baraff, E. O. Kane, and M. Schlüter, Phys. Rev. B 21, 5662 (1980).

16J. R. Troxell and G. D. Watkins, Phys. Rev. B 22, 921 (1980).

${ }^{17}$ L. C. Kimerling, P. Blood, and W. M. Gibson, in Defects and Radiation Effects in Semiconductors, 1978, Institute of Physics Conference Series No. 46, edited by J. H. Albany (IOP, Bristol and London, 1979), p. 273.

${ }^{18}$ M. J. Puska, C. Corbel, and R. M. Nieminen, Phys. Rev. B 41, 9980 (1990).

${ }^{19}$ See, e.g., P. Hautojärvi and A. Vehanen, in Ref. 9.

${ }^{20}$ H. E. Hansen, R. Talja, H. Rajainmäki, H. K. Nielsen, B. Nielsen, and R. M. Nieminen, Appl. Phys. A 36, 81 (1985).

${ }^{21}$ P. Kirkegaard, M. Eldrup, O. E. Mogensen, and N. J. Pedersen, Comput. Phys. Commun. 23, 307 (1981).

${ }^{22}$ U. Littmark and J. F. Ziegler, Handbook of Range Distribu- tions for Energetic Ions in All Elements (Pergamon, New York, 1980).

${ }^{23}$ W. Fuhs, U. Holzhauser, S. Mantl, F. W. Richter, and R. Sturm, Phys. Status Solidi B 89, 69 (1978).

${ }^{24}$ S. Dannefaer, in Radiation Effects and Defects in Solids, edited by J. T. Borenstein (Gordon and Breach, London, 1989), Vols. 111 and 112 .

${ }^{25}$ S. Dannefaer, P. Mascher, and D. Kerr, Phys. Rev. Lett. 56, 2195 (1986).

${ }^{26}$ M. J. Puska, S. Mäkinen, M. Manninen, and R. M. Nieminen, Phys. Rev. B 39, 7666 (1989).

${ }^{27}$ J. Mäkinen, C. Corbel, P. Hautojärvi, P. Moser, and F. Pierre, Phys. Rev. B 39, 10162 (1989).

${ }^{28}$ S. Dannefaer, G. W. Dean, D. P. Kerr, and B. G. Hogg, Phys. Rev. B 14, 2709 (1976).

${ }^{29}$ R. Würschum, W. Bauer, K. Maier, A. Seeger, and H.-E. Schaefer, J. Phys. Condens. Matter 1, SA33 (1989).

${ }^{30} \mathrm{~S}$. Dannefaer, in Proceedings of the Eighth International Conference on Positron Annihilation, edited by L. DorikensVanpraet, M. Dorkens, and D. Segers (World Scientific, Singapore, 1989), p. 86.

${ }^{31}$ See, e.g., R. N. West, in Ref. 9, p. 89.

${ }^{32}$ G. D. Watkins, in Deep Centers in Semiconductors, A State-ofthe-Art Approach, edited by S. T. Pantelides (Gordon and Breach, New York, 1986), p. 147.

${ }^{33}$ M. J. Puska, O. Jepsen, O. Gunnarsson, and R. M. Nieminen, Phys. Rev. B 34, 2695 (1986).

${ }^{34}$ Y-H. Lee and J. W. Corbett, Phys. Rev. B 13, 2653 (1976).

35 J. W. Corbett, J. K. Karins, and T. Y. Tan, Nucl. Instrum. Methods 182\&183, 457 (1981).

${ }^{36}$ G. D. Watkins and J. W. Corbett, Phys. Rev. 134, A1359 (1964).

${ }^{37}$ L. C. Kimerling, H. M. DeAngelis, and J. W. Diebold, Solid. State Commun. 16, 171 (1975).

${ }^{38}$ M. J. Puska and R. M. Nieminen, J. Phys. F 13, 333 (1983).

${ }^{39}$ M. J. Puska, Phys. Status Solidi A 102, 11 (1987).

${ }^{40}$ R. M. Gibb, G. J. Rees, B. W. Thomas, B. L. H. Wilson, B. Hamilton, D. R. Wight, and N. F. Mott, Philos. Mag. 36, 1021 (1977).

${ }^{41}$ M. Lax, Phys. Rev. 119, 1502 (1960).

${ }^{42}$ S. Dannefaer, S. Kupca, B. G. Hogg, and D. P. Kerr, Phys. Rev. B 22, 6135 (1980).

${ }^{43}$ P. Mascher, S. Dannefaer, and D. Kerr, Phys. Rev. B 40, 11764 (1989).

${ }^{44}$ W. Brandt, Appl. Phys. 5, 1 (1974).

${ }^{45}$ W. Fuhs, U. Holzhauser, and F. W. Richter, Appl. Phys. 22, 415 (1980).

${ }^{46}$ R. M. Nieminen and M. Manninen, in Ref. 9.

${ }^{47}$ K. L. Brower, Phys. Rev. B 1, 1908 (1970); R. E. McKeighen and J. S. Koehler, ibid. 4, 462 (1971). 